\title{
LIFE CYCLE SUSTAINABILITY ASSESSMENT FOR MULTI-CRITERIA DECISION MAKING IN BRIDGE DESIGN: A REVIEW
}

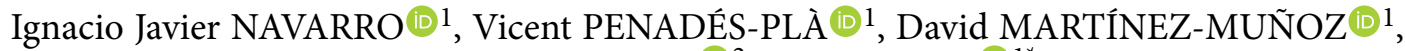 \\ Rasmus REMPLING ${ }^{2}$, Víctor YEPES (1) $1^{*}$ \\ ${ }^{1}$ ICITECH, Department of Construction Engineering, Universitat Politècnica de València, Valencia 46022, Spain \\ ${ }^{2}$ Chalmers University of Technology, Civil and Environmental Engineering, Structural Engineering, \\ Gothenburg, Sweden
}

Received 11 June 2020; accepted 18 September 2020

\begin{abstract}
Sustainable design of infrastructures has become a major matter of study since the recent establishment of the Agenda 2030. This paper provides a systematic literature review on the use of multi-criteria decision making techniques used so far for the sustainable design of bridges. Special attention is put as well on how the reviewed studies assess the sustainable performance of bridge designs along their life cycle from the economic, the environmental and the social perspective. Although SAW and AHP are recurrently used in the sustainable assessment of bridges, the analysis of the most recent articles show that the application of TOPSIS and PROMETHEE techniques are gaining increasing relevance for such purpose. Most of the studies focus on the research of the construction and the maintenance stage of bridges. However, a need for further analysis is identified when it comes to the assessment of the impacts resulting from the End of Life cycle stage of bridges from a sustainable point of view. The use of intuitionistic and neutrosophic logic have been detected as emerging alternatives to the fuzzy approach of decision making problems.
\end{abstract}

Keywords: decision making, sustainability, bridge design, state of the art, MCDM, life cycle assessment.

\section{Introduction}

The recently established Sustainable Development Goals (SDG) in the Agenda 2030 claim for a paradigm shift in the way things are done: sustainable designs and decisions shall now seek solutions that maximise benefits and reduce negative impacts over time in the so-called three dimensions of sustainability, namely economy, environment and society. This is especially relevant in the field of infrastructures, as revealed by the ninth SDG, which explicitly requires the design of infrastructures to be sustainable by 2030. The achievement of this particular SDG has been recognised as an essential step towards the establishment of the sustainable future sought by the Agenda 2030, given that the construction sector is one of the main economic and environmental stressors (Schmidt \& Osebold, 2017; Huang et al., 2020; Choi, 2019) existing nowadays. In particular, although research is conducted on the sustainability analysis of a variety of infrastructure types, such as retaining walls (Zastrow et al., 2017), road pavements (Ozcan-Deniz \& Zhu, 2015; Torres-Machi et al., 2017), buildings (Sánchez-Garrido \& Yepes, 2020) and others, special emphasis has been put in recent times on the sustainable design of bridges. The relevance of the sustainability of bridges is due to the fact that bridges are essential elements in the transportation infrastructure and the transport sector is recognised as the second largest source of carbon dioxide emissions (Torres-Machi et al., 2017). Therefore, research has been conducted on the assessment of the impacts resulting from the construction and maintenance of bridges in each of the three dimensions of sustainability. Efforts have been made to reduce the economic impacts of bridges by optimising the costs associated both to construction (García-Segura et al., 2014; Penadés-Plà et al., 2020a) and to maintenance (Sabatino et al., 2016; Navarro et al., 2018a). The environmental dimension of sustainability has also been assessed in studies focused on finding the most favourable design geometry (GarcíaSegura et al., 2017a; Yepes et al., 2015) and maintenance strategy (Navarro et al., 2018b, 2019a). Hammervold et al. (2013) compare the environmental impacts along the life cycle of three bridges considering routine maintenance.

${ }^{\star}$ Corresponding author. E-mail: vyepesp@cst.upv.es 
Zhang et al. (2016) take into account the uncertainties associated to environmental impact assessment. Only in the last few years, research has been also conducted on the assessment of social impacts related to construction and maintenance of bridges (Navarro et al., 2020; Penadés-Plà et al., 2020b) and roads (Sierra et al., 2017). Gervásio and da Silva (2013) also assess the social dimension of bridge design by incorporating social life cycle impacts in the form of transport externalities derived from maintenance activities.

The evaluation of sustainability requires, however, not only of an appropriate assessment of each individual dimension of sustainability, but of the simultaneous consideration of each of them as well. Given that sustainable assessment relies on criteria of very different nature that are usually in conflict (Salas \& Yepes, 2020), the application of Multi-Criteria Decision-Making (MCDM) methods has aroused as an essential assessment tool when it comes to sustainable design (Cinelli et al., 2014). The use of MCDM techniques has been widely used over the last decades in the field of engineering because of their advantages in handling miscellaneous information, in involving a variety of stakeholders' preferences in the decision-making process, and in considering unconnected criteria and uncertain assessment scenarios (Zavadskas et al., 2016a, 2016b). In recent years, Zavadskas et al. (2016c, 2016d) and Jato-Espino et al. (2014) reviewed the application of such methods to solve different civil engineering and construction problems. Its application on the sustainability assessment of infrastructures is, however, much more recent. Navarro et al. (2019b) and Zavadskas et al. (2018) reviewed the use of MCDM in studies focused on the design of sustainable infrastructures attending to the different dimensions of sustainability along the life cycle of the structures. Both studies reveal a significant increase in the number of research articles published since 2015, coinciding with the year of establishment of the Agenda 2030 and the SDGs. However, less attention has been paid to the application of MCDM techniques applied to the sustainable design of bridges in recent times (Penadés-Plà et al., 2016). The present paper provides an updated, comprehensive review of the state of the art regarding the use of MCDM methods for the sustainable design of bridges. Special focus is put on how the different sustainability dimensions are assessed when designing bridges, paying attention on the particular criteria considered in the literature. Given the relevance of bridges as key elements of the infrastructure system, the present review is intended to provide a consistent overview of the actual State of the Art, revealing knowledge gaps that need to be addressed in order to be able to achieve the ninth SDG of the Agenda 2030, namely the design of sustainable infrastructures.

The rest of the paper is structured as follows. Section 1 presents the methodology of the research, describing data sampling strategy followed. In Section 2, results are presented. In particular, Section 2.1 provides a general overview of the acquired data. Section 2.2 investigates how sustainability is assessed in the analysed manuscripts, pay- ing special attention on the sustainability dimensions assessed and the criteria used to characterise each of them. Section 2.3 presents the life cycle stages analysed in the studies under review. Section 2.4 describes the MCDM techniques applied and its distribution over time. Section 2.5 presents a brief review on how the subjectivity of decision-making problems is handled. Section 3 provides a statistical discussion of the obtained results. Final section provides the conclusions of the present literature review.

\section{Materials and methods}

The data sampling strategy followed in the present systematic literature review consists of two main stages. The first stage is intended to provide an initial set of articles obtained through the application of a particular search algorithm. In a second step, this set is then expanded through an appropriate filtering and selection process. The review is entirely focused on manuscripts refereed in SCOPUS academic database. The search period is established from 1990 to 2020. The search algorithm used for the present review for the construction of the initial set of papers consists of a combination of three differentiated terms connected by the Boolean operators AND and OR. The first type of term includes concepts such as Multi-criteria decision making or MCDM. The second concept systematically considered in the algorithm is obtained from a term-vector that includes 14 specific MCDM techniques, such as TOPSIS, ELECTRE, PROMETHEE, VIKOR, and others. Finally, the third term is related to the particular engineering field of interest for the present paper, namely Bridge.

Some exclusion criteria are applied to filter the results obtained and build the preliminary set of manuscripts. First, only peer-reviewed articles are included in the set. The obtained results are additionally filtered for the SCOPUS database category Engineering. It shall be highlighted that the present study only considers articles written in English. The resulting set of 157 papers is then qualitatively filtered considering two additional exclusion/acceptance rules. Firstly, those manuscripts that do not clearly identify the MCDM technique used are excluded from the set. Second, for the papers to be accepted, their research scope shall be directly related to the sustainable design of bridges. It is relevant to note that the concept of sustainability was consciously not included in the search algorithm, but considered qualitatively as exclusion criteria. If considered in the algorithm, the initial set of papers would have resulted in such a reduced number of papers that it would have been impractical to work with. The described filtering process resulted in an initial set of 31 articles.

Once this initial set is obtained, the references included in each of the accepted manuscripts are then analysed. The filtering process described above is applied to each of them, so that finally an expanded set is constructed. The final expanded set consists of 62 articles that have explicitly applied MCDM techniques for the sustainabilityoriented design of bridges up to 2020 (see Figure 1). 


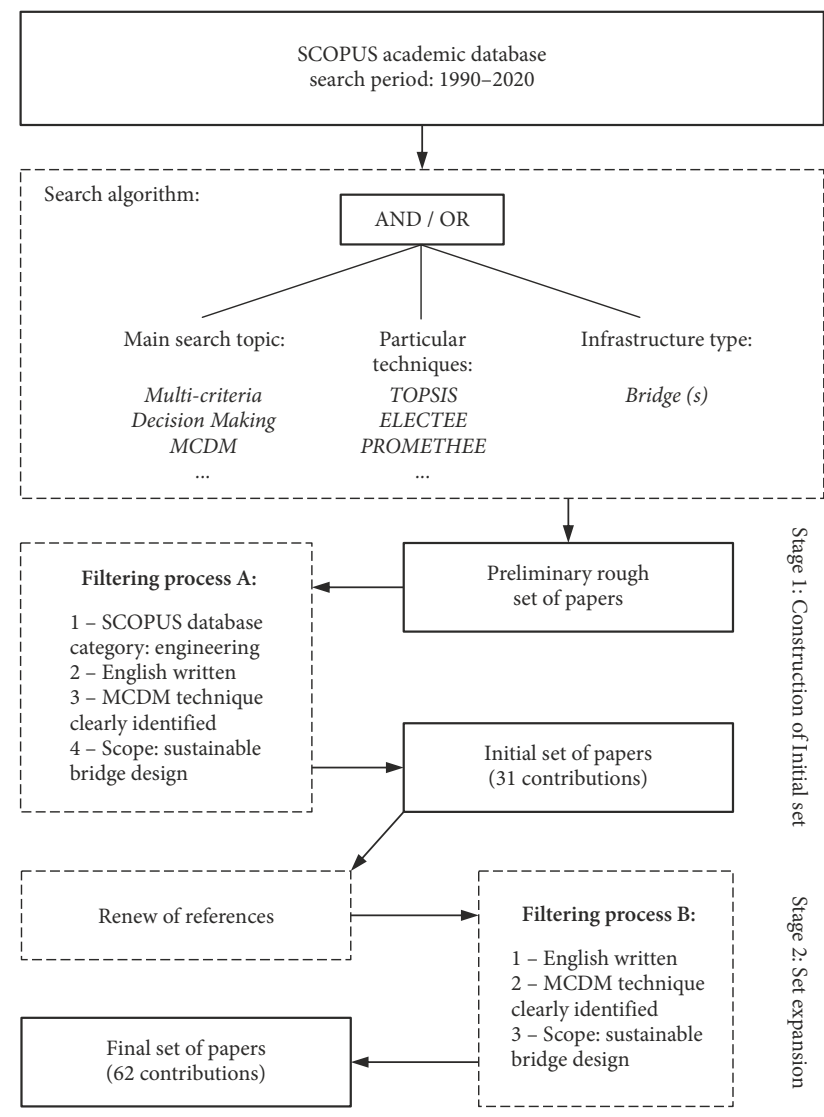

Figure 1. Flowchart illustrating the systematic data sampling process

\section{Results}

\subsection{Overview of the results}

The first research found dealing with MCDM techniques applied to the sustainable design of bridges is dated in 1994 (Sobanjo et al., 1994). Since then, the number of yearly publications on that topic has been scarce until 2008, when a first significant rebound is observed (Figure 2). A second relevant rebound is observed between 2014 and 2015. It is found that almost 50\% of the total amount of publications are condensed between 2015 and the present. This is coincident with the fact that in 2015 the Sustainable Development Goals were established by the General Assembly of the United Nations, thus increasing the interest of the scientific community on that area of research.

Figure 3 shows the number of publications by country. It is observed that, in terms of the number of publications, the countries that have most contributed to the application of MCDM techniques for the sustainable design of bridges are the United States (12 articles), China (10 articles) and Taiwan ( 9 articles), followed by Iran ( 6 articles) and Spain (5 articles).

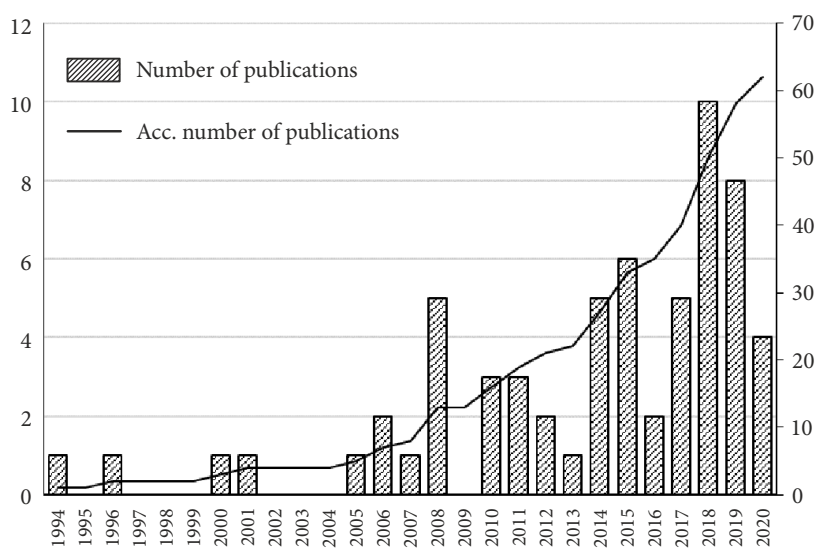

Figure 2. Distribution of publications over time (1994-2020)

156 authors have been involved in the development of the 61 selected manuscripts on the topic of this review. Table 1 shows the 15 authors that have published more than one paper, as well as their institution and their countries.

MCDM are used to assess variety bridge design-related aspects from the point of view of sustainability. A first group of authors is identified that focus their studies on the analysis of rehabilitation strategies, such as Sobanjo et al. (1994), Chassiakos et al. (2005), Dabous and Alkass (2008), Yehia et al. (2008), Jajac et al. (2017), Bukhsh et al. (2018, 2019), Contreras-Nieto et al. (2019), and Pipinato et al. (2020). Rashidi et al. (2017) focus their research on the sustainability of different maintenance options on steel bridges. Dabous and Alkass (2010, 2011), Liu et al.

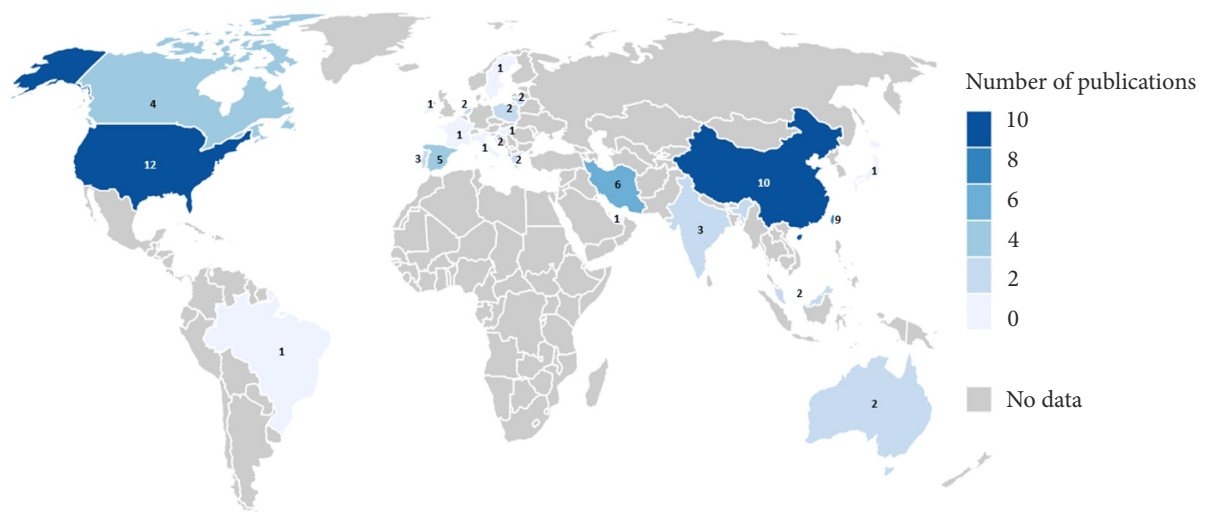

Figure 3. Distribution of publications by country 
(2018) and Chou et al. (2013) approach the maintenance and investment problem from the point of view of bridge network planning. Fabianowski and Jakiel (2019) also devote their study to the sustainable assessment of different management strategies affecting a network of existing railroad bridges.

Other authors apply MCDM techniques for the sustainable assessment of different materials for the design of bridges (El-Mikawi \& Mosallam, 1996; Navarro et al., 2018a, 2018b, 2018c, 2020; Enfedaque et al., 2018). A main source of decision-making problems has been found to be the selection of the bridge type (Itoh et al., 2000; Ugwu et al., 2006; Wang et al., 2010; Balali et al., 2014; Kripka et al., 2019; Farkas, 2011; Gu et al., 2011; Arya et al., 2015) or construction techniques (El-Diraby \& O'Connor, 2001; Pan, 2008; Salem et al., 2018; Jia et al., 2018; Mousavi et al., 2014; Chen, 2018, 2020). Ardeshir et al. (2014) apply fuzzy AHP for the selection of an adequate bridge construction site considering sustainable criteria. Malekly et al. (2010) apply MCDM to choose the best superstructure design alternative by combining Quality Function Deployment with TOPSIS. Gervásio and da Silva (2012) explicitly include in the sustainability assessment the uncertainties associated with the criteria evaluation. Senapati and Yager (2019) and Chen (2019) apply novel fuzzy MCDM methods for the evaluation of different construction alternatives of a bridge. Rempling et al. (2019) propose a novel automatised design methodology focusing on the minimisation of economic costs and environmental impacts of bridges.

Some authors applying MCDM techniques devote their studies on the risk assessment of bridges from a sustainable perspective (Wang \& Elhag, 2006, 2007; Wang et al., 2008; Peng, 2019; Shen et al., 2016). Sabatino et al. (2015) assess the risk of a particular bridge design using the multi-attribute decision-making technique. Yadollahi et al. (2015) assess the sustainability of an existing bridge, namely the Penang Second Bridge in Malaysia. Aghdaie et al. (2012) assess the sustainability of a footbridge in Sari City, in Iran. Different construction methods for a particular case study have been assessed from a sustainable perspective assuming an intuitionistic fuzzy method with likelihood preferences by Chen $(2014,2015,2016)$ and Wang \& Chen (2015). Bansal et al. (2017) assess the sustainability of two bridge projects under construction in Delhi over the Yamuna River. Tan et al. (2020) investigates the management of the recently collapsed Zijin Bridge in China, including sustainable criteria in the evaluation.

Sasmal and Ramanjaneyulu (2008) apply fuzzy-based AHP for the condition evaluation of concrete bridges. Jakiel and Fabianowski (2015) and Keshavarz-Ghorabaee et al. (2018) have used such approach for the sustainable assessment of alternative bridge design options. The Analytic Network Process is used by Chen et al. (2014) for the sustainable assessment of different demolition options of a bridge. Wang (2017) evaluates the sustainability of different construction materials suppliers for bridges based on so-called alpha sets. Cau and Hong (2017) apply group decision-making methods to evaluate different investment alternatives for a particular bridge case study. Kifokeris et al. (2018) also assess the condition and quality of an existing bridge based on a group decision-making process. Wang et al. (2018) includes the risk attitudes of experts in the decision-making process.

\subsection{Distribution based on the sustainability dimension assessed}

As derived from its first definition in 1987 (World Commission on Environment and Development [WCED], 1987), sustainability involves three differentiated dimensions, namely the economic, the social and the environmental one. These dimensions are usually in conflict, and

Table 1. Authors per number of publications

\begin{tabular}{|l|c|l|l|}
\hline \multicolumn{1}{|c|}{ Author } & Number of publications & \multicolumn{1}{c|}{ Institution } & \multicolumn{1}{c|}{ Country } \\
\hline Chen, T. Y. & 7 & Chang Gung University & Taiwan \\
\hline Alkass, S. & 3 & United Arab Emirates University & United Arab Emirates \\
\hline Elhag, T. M. S. & 3 & Heriot-Watt University & United Arab Emirates \\
\hline Wang, Y. M. & 3 & Fuzhou University & China \\
\hline Yepes, V. & 3 & Universitat Politècnica de València & Spain \\
\hline Dabous, S. A. & 2 & University of Sharjah & United Arab Emirates \\
\hline Fabianowski, D. & 2 & Politechnika Opolska & Poland \\
\hline Frangopol, D. M. & 2 & Lehigh University & United States \\
\hline Gervásio, H. & 2 & University of Coimbra & Portugal \\
\hline Jakiel, P. & 2 & Politechnika Opolska & Poland \\
\hline Klanker, G. & 2 & Rijkswaterstaat & Netherlands \\
\hline Martí, J. V. & 2 & Universitat Politècnica de València & Spain \\
\hline Navarro, I. J. & 2 & Universitat Politècnica de València & Spain \\
\hline Stipanovic, I. & 2 & University of Twente & Netherlands \\
\hline Zavadskas, E. K. & 2 & Vilnius Gediminas Technical University & Lithuania \\
\hline
\end{tabular}


MCDM techniques are required to account for each of them in the achievement of sustainable solutions. In line with that, $66 \%$ of the reviewed articles conduct three-dimensional assessments, while $10 \%$ of them (six articles) base their results in one-dimensional approaches. The remaining $24 \%$ of the articles account for two sustainability dimensions simultaneously. Figure 4 shows the distribution over time of the number of publications basing their studies on one-, two- or three-dimensional approaches. It is observed that, since 2015 , the number of papers conducting a three-dimensional assessment approach has increased $273 \%$, which doubles the increase ratio observed for the other two approaches. Such observation is in line with the increasing interest on sustainability and sustainable solutions in civil engineering since the establishment of the SDG.

Attention is paid to the criteria that are considered in the analysed studies for the assessment of each dimension of sustainability. The criteria considered by the 58 articles that include the economic impacts in their assessments are based on the direct costs derived from the construction of the bridge, from its maintenance along its service life, or from its demolition. It can be observed that, but for the economic dimension, there is no consensus regarding which criteria shall be used when assessing the environmental and the social impacts of bridges. 48 articles include environmental criteria in their studies. For the purpose of the present analysis, the variety of environmental impacts considered in the reviewed papers are grouped into 8 categories (Figure 5), namely emission of pollutants, energy consumption, material consumption, solid waste generated, eutrophication, use of land, ozone layer depletion, and "Environmental Impact"/ Unspecified. The environmental criterion that has been used most by the reviewed articles (21 papers) is the emission of pollutants. On the contrary, four authors (Gervásio \& da Silva, 2012; Bukhsh et al., 2018, 2019; Navarro et al., 2020) only consider the impact on the ozone layer depletion derived by construction and maintenance activities of bridges. It is worth noting that, among the articles investigated, only three base their environmental results on the use of specific, recognised environmental impact assessment techniques. On the one hand, Navarro et al. (2020) apply the life cycle impact assessment technique ReCiPe, including

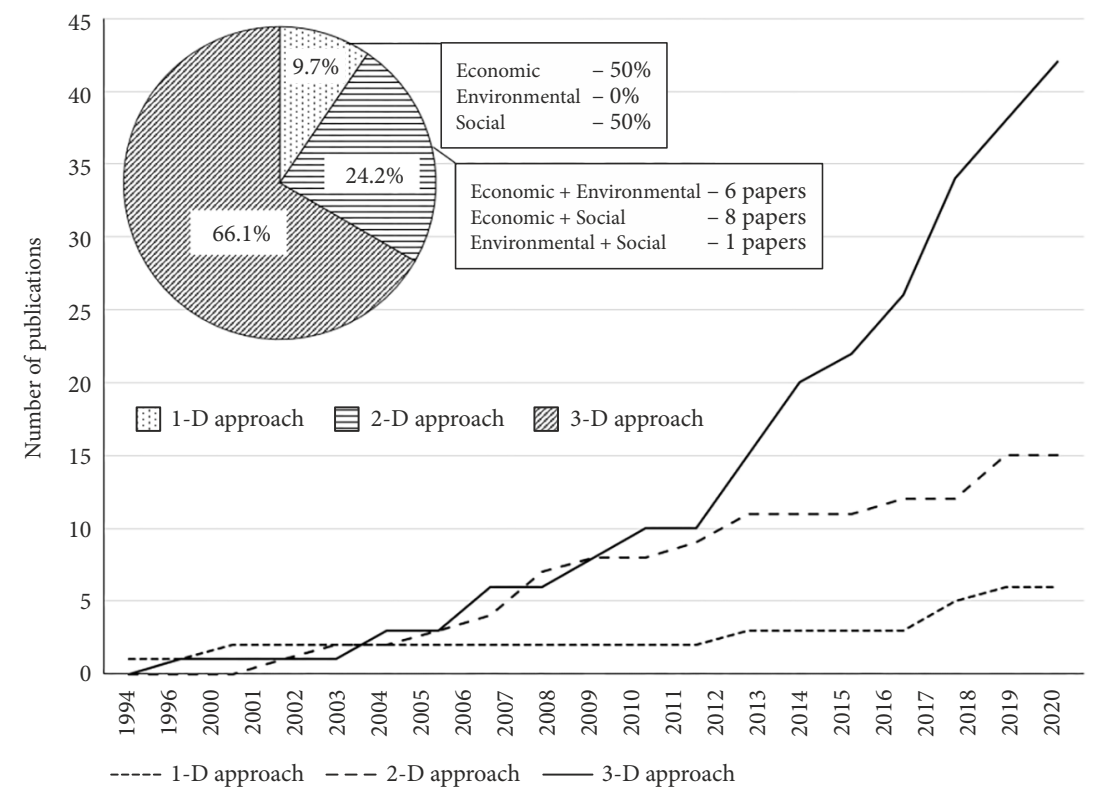

Figure 4. Dimensional approach for the sustainable assessment of bridge designs

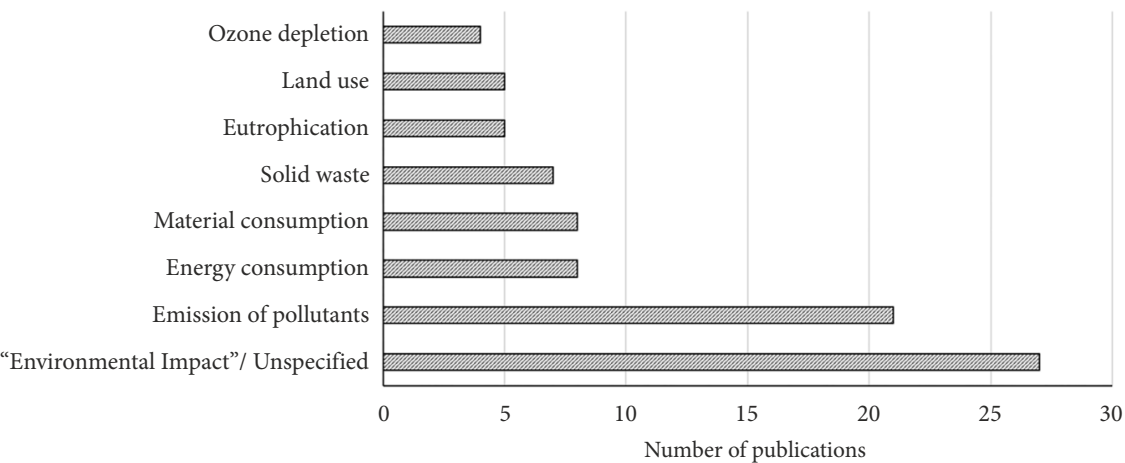

Figure 5. Environmental impact categories considered in the sustainability assessment of bridges 
all the impact categories of such technique in their work and explicitly following the environmental ISO standards for the assessment. On the other hand, Bukhsh et al. (2018, 2019) apply the CML 2001 methodology. It shall be mentioned that Gervásio and da Silva (2012) base their life cycle environmental assessment on the environmental ISO standards, although they do not explicitly mention the impact assessment technique used. Among the 48 articles assessing impacts to the environment, it shall be noted that 27 of them do not explicitly describe neither which particular impacts they are assessing nor how they evaluate them. These have been grouped in Figure 5 under the category "Environmental Impact"/ Unspecified.

Figure 6 presents the nine main categories that have been found to be recurrent in the 53 articles that assess social aspects, namely the impacts on the users of the bridge, aesthetics, the health and safety of both users and workers, externalities derived from construction activities, such as noise, vibrations or dust, the impact on local economies, social wellbeing, culture and heritage preservation, employment of local workforce and innovation. These impact categories are in line with the 33 categories recommended by the UNEP/SETAC (2009) for the five different stakeholders suggested for the social life cycle assessment of products, namely the local communities, the value chain actors, consumers, workers and society. From the abovementioned five stakeholders suggested by UNEP/SETAC (2009), social impacts on local communities are assessed by $39.5 \%$ of the studies, namely those evaluating impacts on cultural heritage, local employment generation, the externalities and the public acceptance of the bridge and its aesthetics. The stakeholder Society is taken into account by $14.3 \%$ of the studies, namely those considering impacts on the development of local economies (Ugwu et al., 2006; Aghdaie et al., 2012; Bansal et al., 2017; Cau \& Hong, 2017; Navarro et al., 2018a, 2018b, 2018c; Salem et al., 2018; Wang et al., 2018), on the social wellbeing and the inclusion of innovation (Wang et al., 2010; Ugwu et al., 2006) in the bridge design. The stakeholder Workers is assessed by $19.3 \%$ of the articles, which consider the health and safety related to working conditions as a main source of social impacts. At last, the stakeholder category Users is accounted by $26.9 \%$ of the studies. The impacts derived along the life cycle of a bridge on the Value Chain Actors are not considered by any of the papers reviewed.

As shown in Figure 6, the most assessed among the abovementioned impact categories are the ones related to users (32 papers), aesthetics (26 papers) and health (23 papers). While the impacts on health and aesthetics or public opinion can be measured with similar metrics regardless of the infrastructure under study, the impacts on users are closely related to the particular type of infrastructure assessed. Being bridges a particular case of transport infrastructure, it has been found common practice among the reviewed studies to assess impacts on users by means of three main metrics: Vehicle Operating Costs, Delay Costs and an unspecified Traffic Disruption metrics.

\subsection{Distribution based on life cycle stage assessed}

The sustainable design of products requires a life-cycle approach to analyse and evaluate the impacts derived from it over time. This life-cycle perspective is particularly relevant when it comes to the assessment of infrastructures, where designs are required to provide long-lasting structures that resist over $50-100$ years. The relevant life cycle stages common in the assessment of any infrastructure are the construction phase, the use stage and the End of Life or Demolition stage. In recent times, and for the particular case of bridges, it has been shown that both the impacts associated to construction, as well as those related to the maintenance and End of Life stage of their life cycles result in significant economic, environmental and social impacts (Frangopol \& Soliman, 2016; García-Segura et al., 2017b; Penadés-Plà et al., 2017). Figure 7 shows the number of publications that have considered one, two or the three stages of bridges life cycle in their studies, as well as their distribution over time.

Only two articles (3\% of the total amount of articles reviewed) have been found that explicitly consider the three bridge life-cycle stages (Gervásio \& da Silva, 2012; Navarro et al., 2020) when assessing sustainability. On the contrary, $68 \%$ of the articles reviewed base their studies on the sole consideration of one life-cycle stage, assessing the impacts derived either from the construction or from the use stage. It is observed that the most assessed life-cycle



Figure 6. Social impact categories considered in the sustainability assessment of bridges 


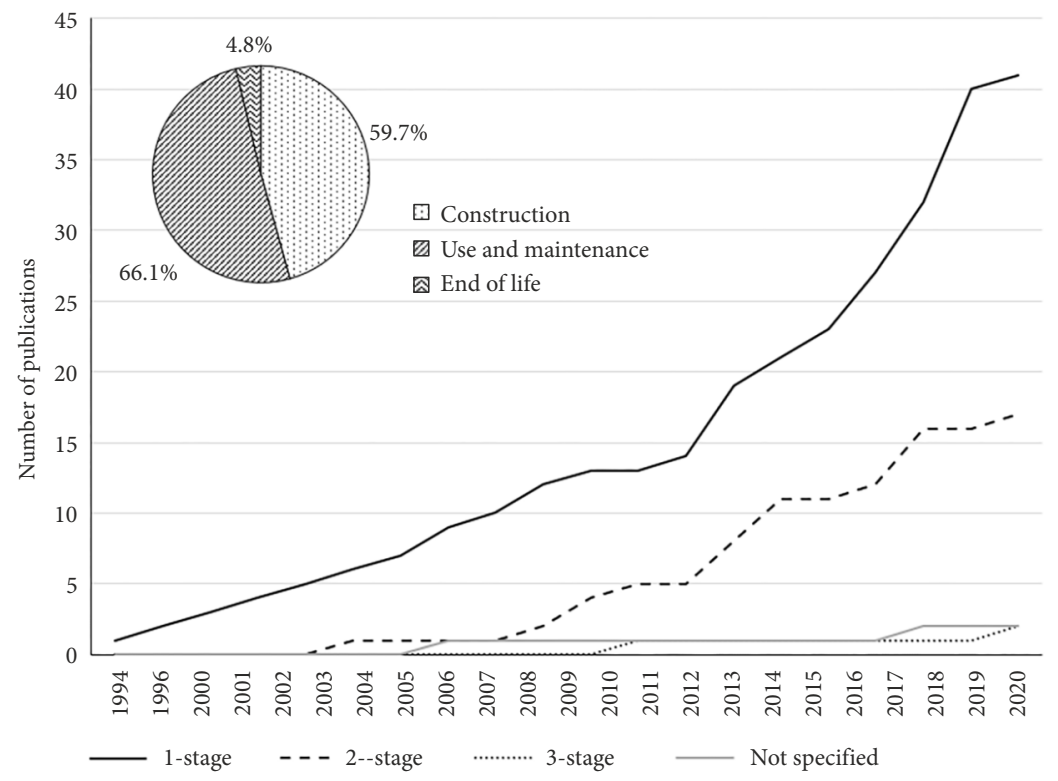

Figure 7. Life Cycle stages analysed over time in sustainability assessment of bridges

stage is the maintenance phase, considered by $66 \%$ of the reviewed articles. The impacts derived from the construction stage where considered in $60 \%$ of the articles, while the least assessed stage is the End-of-Life, accounted by only $4.8 \%$ of the studies.

\subsection{Distribution based on the MCDM method applied}

MCDM methods shall be classified into five main categories, namely scoring methods, distance-based methods, those based on pairwise comparison, outranking methods and utility methods. Scoring methods are based on the direct application of basic arithmetic to find the preferred solution in multi-criteria problems. Simple Additive Weighting (SAW) and Complex Proportional Assessment (COPRAS) are examples classified under this category. Distance-based methods obtain the best solution evaluating its distance to both the optimal and the worst existing solution. Examples of such methods are the Technique for Order of Preference by Similarity to Ideal Solution (TOPSIS) or the Multi-criteria Optimization and Compromise Solution (VIKOR). There are methods that entirely base the decision on the pairwise comparison between alternative solutions, such as the Analytic Hierarchy Process (AHP) or the Analytic Network Process (ANP). Outranking methods, such as the Preference Ranking Organization Method for Enrichment of Evaluations (PROMETHEE) or the Elimination and Choice Expressing Reality Method (ELECTRE) base the decision on the establishment of a degree of dominance between alternatives. At last, MultiAttribute Utility method (MAUT) is an example of the utility-based MCDM methods that base the preference on the degree of satisfaction expected by each alternative.

The MCDM techniques used when assessing the sustainability of bridges are presented in Figure 8. It is observed that most of the reviewed articles apply scor-

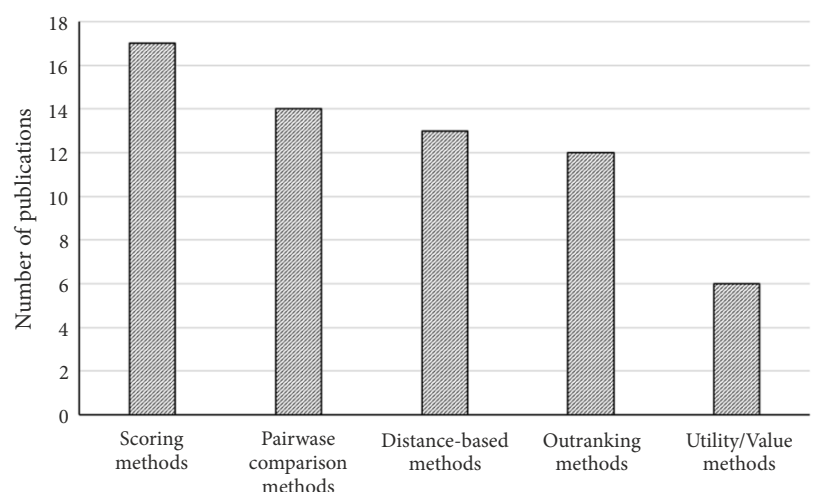

Figure 8. MCDM methods used in sustainable design of bridges by category

ing methods in their studies. In view of the results, it is derived that there is no clear preference for one of the decision-making methods, as the remaining techniques are used by approximately $20 \%$ of the reviewed papers each. There is, indeed, a significant difference when it comes to the less used techniques, namely those based on the utility, which are used by only $10 \%$ of the studies.

Figure 9 shows the distribution of the use of the particular decision-making techniques over time on the topic of sustainable design of bridges. Results are presented for those techniques that have been used in more than two studies, namely AHP, SAW, TOPSIS, MAUT, PROMETHEE and VIKOR. 11 articles have applied a variety of other techniques, which have not been included in Figure 9 for the sake of simplicity. It is noted that the most used MCDM method is the direct application of AHP, which has been used to derive preferences among alternative solutions by $24 \%$ of the reviewed publications. It is observed that its application is relatively constant over time. SAW is the second most applied technique, used by $18 \%$ of the authors. In spite of the significant use of SAW in decision 
making problems, due to its ease of use and understanding, during the last years there is an increasing interest in the use of other alternative techniques. Such is the case of TOPSIS, MAUT or VIKOR, whose application in sustainable bridge design has increased significantly since 2016 .

\subsection{Distribution based on logic applied}

Great concern has arisen in recent times regarding the subjectivity related to some MCDM process steps and how this affects in the final decision making. Criteria weighting is by far the most subjective step in decision making, as experts are usually required to provide judgements upon which weights are determined. The use of the conventional logic (i.e. the so-called crisp numbers) presumes every assignment to be certain and precise. However, when it comes to complex decision making problems, such as those related with sustainability, this assumption has become object of strong criticism (Radwan et al., 2016). As a means to model and include the non-probabilistic uncertainties associated to subjective judgements, alternative mathematical logics have been used during the past years to handle linguistic variables and deal with the vagueness of human thinking (Fallahpour et al., 2020; del Caño et al., 2016).
Figure 10 shows how different mathematical logics have been incorporated in the sustainability assessment of bridges and its distribution over time. Although the majority of studies base their results on the use of crisp $\operatorname{logic}, 38 \%$ of the reviewed manuscripts incorporate fuzzy logic in their assessments. It can be observed that the application of fuzzy logic in the sustainable design of bridges follows an almost parallel evolution if compared to the application of crisp numbers. It is observed that, in recent times, other alternative, more complex logics have been used to mathematically model the subjectivity in decision making problems. So, grey numbers have been used by Aghdaie et al. (2012). The intuitionistic numbers are a generalisation of the fuzzy numbers, and allow modelling a wider range of subjective judgements. Intuitionistic logic has been applied by almost $7 \%$ of the reviewed studies since 2014 (Chen, 2015, 2016; Shen et al., 2016; Chen et al., 2014). Only in very recent times, neutrosophic logic has been applied as a further generalisation of the fuzzy and intuitionistic logic, as it allows modelling a wide variety of judgements, such as contradictory or paradox statements. Neutrosophic logic has been implemented in only one study devoted to the sustainability assessment of different bridge design alternatives in coastal environments (Navarro et al., 2020).



Figure 9. Distribution over time of the main MCDM techniques used in sustainable bridge designs

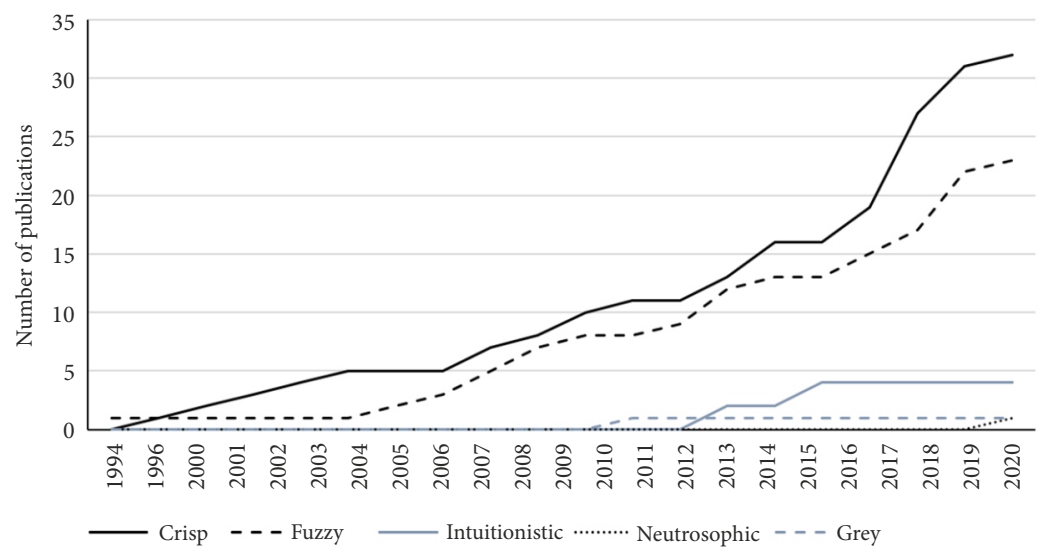

Figure 10. Distribution over time of the mathematical logic used to model subjectivity in sustainable decision-making related to bridge designs 


\section{Discussion}

\subsection{Discussion of the results}

The results of the present literature review reveal that AHP is currently the most used technique when dealing with the sustainability of bridges, followed by SAW. The popularity of SAW is due to the ease of its use and interpretation of the results. However, SAW technique shall only be used when all the criteria are maximising. Therefore, when it comes to complex problems, such as those related to the sustainability assessment of long-lasting structures, where criteria are usually in conflict, SAW technique require criteria to be adequately normalised, which is one of the main limitations of this method (Podvezko, 2011). In recent times, the use of other decision-making methods, such as TOPSIS and PROMETHEE, has increased significantly as an alternative to SAW. Similar trends in the use of MCDM techniques are also revealed in other fields of civil engineering related to sustainability. To cite some recent examples, Mardani et al. (2015) detects this trend when analysing MCDM techniques used to solve construction management problems. The review conducted by Kaya et al. (2018) on the MCDM methods used in relation to the selection of energy policies also presents SAW as the most popular technique, followed by TOPSIS and PROMETHEE.

In view of the results, TOPSIS and PROMETHEE seem to provide an interesting alternative to overcome the drawbacks associated to the simple additive weighting, not only in the field of civil engineering, but in other fields as well, such as product recovery (Ilgin et al., 2015) or the automotive industry (Noryani et al., 2018). On the one hand, TOPSIS is a distance-based technique that provides that particular solution that is simultaneously closest to the ideal solution, and farthest to the least desired alternative. The increasing popularity of this method relies on its transparency along the decision-making process and its adequacy to represent the rationale of human thinking. In addition, TOPSIS is a highly flexible method that allows for a comprehensive accommodation to the ever more used fuzzy (Issa et al., 2019; Polat et al., 2017) or neutrosophic (Navarro et al., 2019b) environments, without prejudicing its simplicity of use.

On the other hand, PROMETHEE belongs to the family of outranking multi-criteria methods, where the alternatives under consideration are compared pairwise and scored between 0 and 1 by means of a preference function. This method has experienced several modifications since its first definition to adapt to the different boundaries of the problem to be solved. PROMETHEE III, for example, is intended for those decision making problems where information is partially missing. However, one of the limitations of these methodologies is that they provide not so comprehensive results, and that the ranking of alternatives can significantly change when new options are included (Gervásio \& da Silva, 2012).

Zavadskas et al. (2018) conduct a literature review on the MCDM techniques used in civil engineering to achieve sustainable solutions, also resulting in AHP and
TOPSIS to be the most popular techniques. Zavadskas et al. (2016b) when analysing the application of MCDM techniques in civil engineering obtained similar results.

\subsection{Statistical discussion}

A correspondence analysis of the presented results is conducted in order to reveal the statistical relations that exist between them. Particular attention is paid to the relations existing between the MCDM techniques used, the sustainability dimensions assessed and the life cycle stages considered in the studies included in this review. Figure 11 shows the correspondence relations between the variables Life-cycle stage and the MCDM category used for the sustainability assessment. Two variables can be identified that clearly show a greater statistical inertia in relation to the others, namely the variables called End of Life and the Utility/Value. It can be observed that, while the reviewed articles similarly address both the construction and the maintenance stage, the end of life stage is only marginally considered in the studies. In fact, only three manuscripts account for this life cycle stage in their sustainability assessments. Penadés-Plà et al. (2016) have previously reported similar results in a literature review conducted on MCDM techniques used for the sustainable design of transport infrastructures.

On the other hand, it can be observed that, in statistical terms, the different MCDM categories are indistinctly used in the assessments, but for the case of those based on the use of the multi-attribute utility function. Such techniques have been used only in very recent times in the field of bridges design, as shown in Figure 9, and are used in studies that solely assess the maintenance stage of bridges. Consequently, the use of MAUT in sustainability assessment of bridges shows a relatively reduced inertia with respect to the horizontal axis of the correspondence analysis presented. An exception to this is the study conducted by Dabous and Alkass (2011) that also assesses the construction stage from a sustainable perspective using MAUT. Concerning the remaining variables, namely the life cycle stages Construction and Use and Maintenance, and the rest of the MCDM categories analysed, a similar statistical interaction shall be found between them, although no clear relation shall be derived in view of the results.

The statistical relations between the MCDM category and the sustainability dimension assessed are presented in Figure 12. From the results obtained, it can be derived that the environmental dimension of sustainability is statistically related to the MCDM categories called Outranking and Others. On the contrary, the economic dimension is more usually assessed by means of distance-based and pairwise comparison-based MCDM techniques. As can be observed, MCDM based on scoring is almost used indifferently to assess any of the three sustainability dimensions, but presents a slightly closer statistical distance to the social one. In general, in spite of the relations observed, there is no strong statistical interaction between none of the analysed variables. 


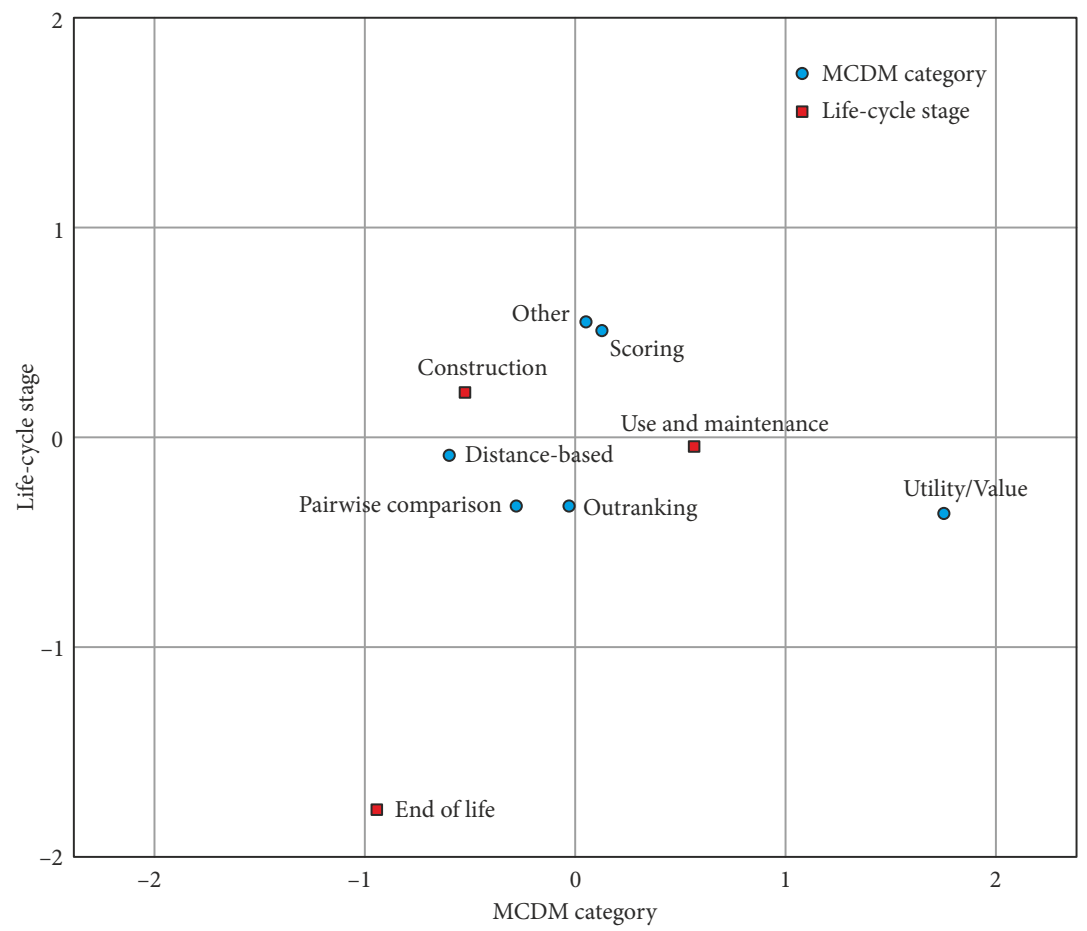

Figure 11. Simple correspondence analysis for life cycle stage assessed and MCDM category used

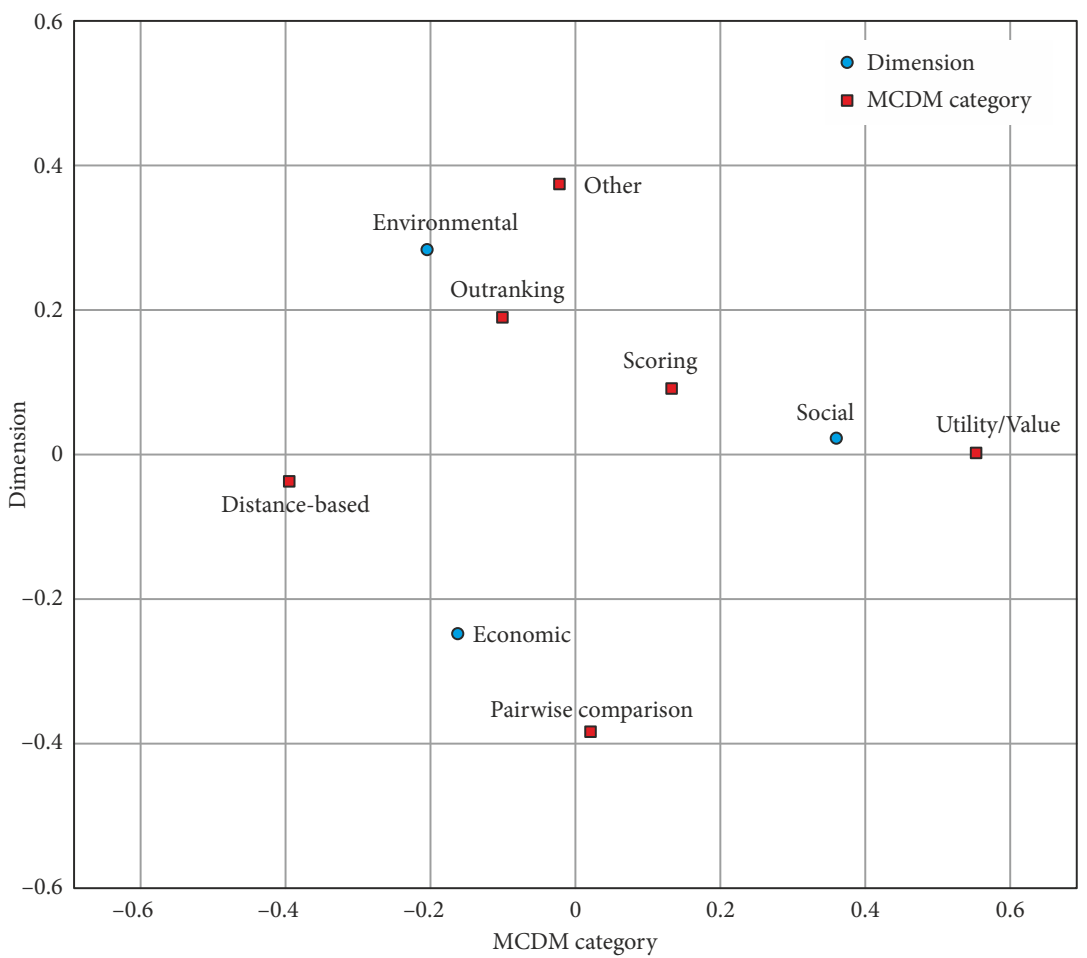

Figure 12. Simple correspondence analysis for sustainability dimension assessed and MCDM category used

\subsection{Limitations of the study}

The present study consists on a systematic literature review. Given the recent strong interest in the field of sustainable design, such systematic studies are advantageous because they can provide a more objective overview of the state of the art through the inclusion of strict inclusion/exclusion rules. However, this is at the same time one of the main limitations of such objective reviews, as the obtained results are influenced by the search algorithms considered and the databases consulted. The present study aims to compensate such limitation through the inclusion of a second searching round, where the original set of articles derived from the systematic revision process (31 contributions) is expanded up to 62 contributions. 


\section{Conclusions}

This paper presents a systematic literature review on the use of MCDM techniques for the sustainability assessment of bridge projects. 62 articles published since 1994 have been examined that address the sustainable design of bridges a decision-making problem. It has been found that the most assessed environmental aspect is the emission of pollutants. It is important to highlight that $47 \%$ of the articles that assess the environmental consequences related to bridge construction and maintenance do not explicitly specify the environmental impacts considered in their studies. Only three articles base their environmental assessments on recognised life cycle impact assessment techniques, such as ReCiPe or CML 2001.

When it comes to assessing the design of bridges from a social perspective, it has been found that most of the studies assess mainly three social impacts, namely those related to the impact of bridge maintenance on users, to the aesthetics of the bridge, and to the health and safety of workers, assessing other socially relevant aspects, such as social wellbeing or economic development of regions, only marginally. An important knowledge gap has been detected, as it has been found that none of the reviewed articles considers the value chain actors in their studies.

It has been observed that most of the reviewed articles base their sustainability assessments on the analysis of the construction or the maintenance life cycle stage of bridges. On the contrary, the End of Life of bridges is only addressed by three articles, thus revealing an important knowledge gap regarding the impacts derived from the demolition and decommissioning of such infrastructures. Such finding is also revealed by the results derived from the statistical correspondence analysis conducted on the analysis of the variables Life Cycle Stage and MCDM method. It has also been observed that, while the fuzzy logic is widely used for the MCDM-based sustainability assessments, the more advanced intuitionistic or neutrosophic logic has been used only to a limited extent.

Regarding the MCDM techniques used in the studies, it has been found that the use of methods based on the multi-attribute utility value is the least applied decisionmaking technique. AHP and SAW have been found to be the most popular decision-making techniques applied so far in the field of sustainable bridge design, followed closely in recent times by TOPSIS and PROMETHEE. In view of the results obtained from the correspondence analysis, it is concluded that, in statistical terms, the different MCDM techniques are indistinctly used when assessing different life cycle stages. An exception to this statement is the use of MAUT, that has mainly been applied for the assessment of the maintenance stage. When it comes to the assessment of the different sustainability dimensions, the correspondence analysis reveals that the environmental perspective is statistically related to the outranking MCDM techniques, while the economic dimension is more usually assessed by means of distance- and pairwise comparison-based MCDM methods.

\section{Funding}

This study was funded by the Spanish Ministry of Economy and Competitiveness, along with FEDER funding (DIMALIFE Project BIA2017-85098-R).

\section{Author contributions}

This paper represents a result of teamwork. The authors jointly designed the research. I.J.N. drafted the manuscript. V. P.-P., D.M.-M., R.R. and V.Y. edited and improved the manuscript until all authors were satisfied with the final version. All authors have read and agreed to the published version of the manuscript.

\section{Disclosure statement}

The authors declare that there are no conflicts of interest regarding the publication of this article.

\section{References}

Aghdaie, M. H., Zolfani, S. H., \& Zavadskas, E. K. (2012). Prioritizing constructing projects of municipalities based on AHP and COPRAS-G: A case study about footbridges in Iran. Baltic Journal of Road and Bridge Engineering, 7(2), 145-153. https://doi.org/10.3846/bjrbe.2012.20

Ardeshir, A., Mohseni, N., Behzadian, K., \& Errington, M. (2014). Selection of a bridge construction site using fuzzy analytical hierarchy process in geographic information system. Arabian Journal for Science and Engineering, 39(6), 4405-4420. https://doi.org/10.1007/s13369-014-1070-2

Arya, C., Amiri, Z., \& Vassie, P. (2015). A new method for evaluating the sustainability of bridges. Proceedings of the Institution of Civil Engineers: Structures and Buildings, 168(6), 441-453. https://doi.org/10.1680/stbu.14.00069

Balali, V., Mottaghi, A., Shoghli, O., \& Golabchi, M. (2014). Selection of appropriate material, construction technique, and structural system of bridges by use of multicriteria decisionmaking method. Transportation Research Record: Journal of the Transportation Research Board, 2431(1), 79-87. https://doi.org/10.3141/2431-11

Bansal, S., Singh, A., \& Singh, S. K. (2017). Sustainability evaluation of two iconic bridge corridors under construction using Fuzzy Vikor technique: A case study. Revista ALCONPAT, 7(1), 1-14. https://doi.org/10.21041/ra.v7i1.171

Bukhsh, Z. A., Stipanovic, I., Palic, S. S., \& Klanker, G. (2018). Robustness of the multi-attribute utility model for bridge maintenance planning. Baltic Journal of Road and Bridge Engineering, 13(4), 404-415.

https://doi.org/10.7250/BJRBE.2018-13.425

Bukhsh, A., Stipanovic, I., Klanker, G., O'Connor, A., \& Doree, A. G. (2019). Network level bridges maintenance planning using Multi-Attribute Utility Theory. Structure and Infrastructure Engineering, 15(7), 872-885. https://doi.org/10.1080/15732479.2017.1414858

del Caño, A., de la Cruz, M. P., Gómez, D., \& Pérez, M. (2016). Fuzzy method for analysing uncertainty in the sustainable design of concrete structures. Journal of Civil Engineering and Management, 22(7), 924-935. https://doi.org/10.3846/13923730.2014.928361 
Cau, B. T., \& Hong, N. T. (2017). A new approach to the multicriteria appraisal of investment alternatives for infrastructure projects. International Journal of Civil Engineering and Technology, 8(11), 982-994.

Chassiakos, A. P., Vagiotas, P., \& Theodorakopoulos, D. D. (2005). A knowledge-based system for maintenance planning of highway concrete bridges. Advances in Engineering Software, 36(11-12), 740-749.

https://doi.org/10.1016/j.advengsoft.2005.03.020

Chen, T. Y. (2014). The extended linear assignment method for multiple criteria decision analysis based on interval-valued intuitionistic fuzzy sets. Applied Mathematical Modelling, 38(78), 2101-2117. https://doi.org/10.1016/j.apm.2013.10.017

Chen, T. Y. (2015). IVIF-PROMETHEE outranking methods for multiple criteria decision analysis based on interval-valued intuitionistic fuzzy sets. Fuzzy Optimization and Decision Making, 14(2), 173-198.

https://doi.org/10.1007/s10700-014-9195-Z

Chen, T. Y. (2016). An interval-valued intuitionistic fuzzy permutation method with likelihood-based preference functions and its application to multiple criteria decision analysis. Applied Soft Computing, 42, 390-409.

https://doi.org/10.1016/j.asoc.2016.02.006

Chen, T. Y. (2018). A novel PROMETHEE-based outranking approach for multiple criteria decision analysis with pythagorean fuzzy information. IEEE Access, 6, 54495-54506. https://doi.org/10.1109/ACCESS.2018.2869137

Chen, T. Y. (2019). Novel generalized distance measure of pythagorean fuzzy sets and a compromise approach for multiple criteria decision analysis under uncertainty. IEEE Access, 7, 58168-58185. https://doi.org/10.1109/ACCESS.2019.2914703

Chen, T. Y. (2020). New Chebyshev distance measures for Pythagorean fuzzy sets with applications to multiple criteria decision analysis using an extended ELECTRE approach. Expert Systems with Applications, 147.

https://doi.org/10.1016/j.eswa.2019.113164

Chen, Z., Abdullah, A. B., Anumba, C. J., \& Li, H. (2014). ANP experiment for demolition plan evaluation. Journal of Construction Engineering and Management, 140(2), 06013005. https://doi.org/10.1061/(ASCE)CO.1943-7862.0000791

Choi, J. (2019). Strategy for reducing carbon dioxide emissions from maintenance and rehabilitation of highway pavement. Journal of Cleaner Production, 209, 88-100. https://doi.org/10.1016/j.jclepro.2018.10.226

Chou, J. S., Pham, A. D., \& Wang, H. (2013). Bidding strategy to support decision-making by integrating fuzzy AHP and regression-based simulation. Automation in Construction, 35, 517-527. https://doi.org/10.1016/j.autcon.2013.06.007

Cinelli, M., Coles, S. R., \& Kirwan, K. (2014). Analysis of the potentials of multi criteria decision analysis methods to conduct sustainability assessment. Ecological Indicators, 46, 138-148. https://doi.org/10.1016/j.ecolind.2014.06.011

Contreras-Nieto, C., Shan, Y., Lewis, P., \& Hartell, J. A. (2019). Bridge maintenance prioritization using analytic hierarchy process and fusion tables. Automation in Construction, 101, 99-110. https://doi.org/10.1016/j.autcon.2019.01.016

Dabous, S., \& Alkass, S. (2008). Decision support method for multi-criteria selection of bridge rehabilitation strategy. Construction Management and Economics, 26(8), 883-893. https://doi.org/10.1080/01446190802071190

Dabous, S. A., \& Alkass, S. (2010). A multi-attribute ranking method for bridge management. Engineering, Construction and Architectural Management, 17(3), 282-291.

https://doi.org/10.1108/09699981011038079
Dabous, S. A., \& Alkass, S. (2011). Managing bridge infrastructure under budget constraints: A decision support methodology. Canadian Journal of Civil Engineering, 38(11), 12271237. https://doi.org/10.1139/111-082

El-Diraby, T. E., \& O'Connor, J. T. (2001). Model for evaluating bridge construction plans. Journal of Construction Engineering and Management, 127(5), 399-405.

https://doi.org/10.1061/(ASCE)0733-9364(2001)127:5(399)

El-Mikawi, M., \& Mosallam, A. S. (1996). A methodology for evaluation of the use of advanced composites in structural civil engineering applications. Composites Part B: Engineering, 27(3-4), 203-215.

https://doi.org/10.1016/1359-8368(95)00030-5

Enfedaque, A., Alberti, M. G., Gálvez, J. C., Rivera, M., \& SimónTalero, J. M. (2018). Can polyolefin fibre reinforced concrete improve the sustainability of a flyover bridge? Sustainability, 10(12), 4583. https://doi.org/10.3390/su10124583

Fabianowski, D., \& Jakiel, P. (2019). An expert fuzzy system for management of railroad bridges in use. Automation in Construction, 106, 102856.

https://doi.org/10.1016/j.autcon.2019.102856

Fallahpour, A., Wong, K. Y., Rajoo, S., Olugu, E. U., Nilashi, M., $\&$ Turskis, Z. (2020). A fuzzy decision support system for sustainable construction project selection: an integrated FPP-FIS model. Journal of Civil Engineering and Management, 26(3), 247-258. https://doi.org/10.3846/jcem.2020.12183

Farkas, A. (2011). Multi-criteria comparison of bridge designs. Acta Polytechnica Hungarica, 8(1), 173-191.

Frangopol, D. M., \& Soliman, M. (2016). Life-cycle of structural systems: recent achievements and future directions. Structure and Infrastructure Engineering, 12, 1-20.

https://doi.org/10.1080/15732479.2014.999794

García-Segura, T., Yepes, V., Martí, J. V., \& Alcalá, J. (2014). Optimization of concrete I-beams using a new hybrid glowworm swarm algorithm. Latin American Journal of Solids and Structures, 11(7), 1190-1205.

https://doi.org/10.1590/S1679-78252014000700007

García-Segura, T., Yepes, V., Frangopol, D. M., \& Yang, D. Y. (2017a). Lifetime reliability-based optimization of post-tensioned box-girder bridges. Engineering Structures, 145, 381391. https://doi.org/10.1016/j.engstruct.2017.05.013

García-Segura, Yepes, V., \& Frangopol, D. M. (2017b). Multiobjective design of post-tensioned concrete road bridges using artificial neural networks. Structural and Multidisciplinary Optimization, 56(1), 139-150.

https://doi.org/10.1007/s00158-017-1653-0

Gervásio, H., \& da Silva, S. (2012). A probabilistic decisionmaking approach for the sustainable assessment of infrastructures. Expert Systems with Applications, 39(8), 7121-7131. https://doi.org/10.1016/j.eswa.2012.01.032

Gervásio, H., \& da Silva, L. S. (2013). Life-cycle social analysis of motorway bridges. Structure and Infrastructure Engineering, 9(10), 1019-1039.

https://doi.org/10.1080/15732479.2011.654124

$\mathrm{Gu}, \mathrm{X}$., Wang, Y., \& Yang, B. (2011). Method for selecting the suitable bridge construction projects with interval-valued intuitionistic fuzzy information. International Journal of Digital Content Technology and its Applications, 5(7), 201-206. https://doi.org/10.4156/jdcta.vol5.issue7.25

Hammervold, J., Reenaas, M., \& Brattebø, H. (2013). Environmental life cycle assessment of bridges. Journal of Bridge Engineering, 18(2), 153-161. https://doi.org/10.1061/(ASCE)BE.1943-5592.0000328 
Huang, M., Zhang, X., Ren, R., Liao, H., Zavadskas, E. K., \& Antucheviciene, J. (2020). Energy-saving building program evaluation with an integrated method under linguistic environment. Journal of Civil Engineering and Management, 26(5), 447-458. https://doi.org/10.3846/jcem.2020.12647

Ilgin, M. A., Gupta, S. M., \& Battaïa, O. (2015). Use of MCDM techniques in environmentally conscious manufacturing and product recovery: state of the art. Journal of Manufacturing Systems, 37, 746-758.

https://doi.org/10.1016/j.jmsy.2015.04.010

Issa, U. H., Miky, Y. H., \& Abdel-Malak, F. F. (2019). A decision support model for civil engineering projects based on multi-criteria and various data. Journal of Civil Engineering and Management, 25(2), 100-113.

https://doi.org/10.3846/jcem.2019.7551

Itoh, Y., Sunuwar, L., Hirano, T., Hammad, A., \& Nishido, T. (2000). Bridge type selection system incorporating environmental impacts. Journal of Global Environment Engineering, 6, 81-101.

Jajac, N., Rogulj, K., \& Radnic, J. (2017). Selection of the method for rehabilitation of historic bridges - A decision support concept for the planning of rehabilitation projects. International Journal of Architectural Heritage, 11(2), 261-277. https://doi.org/10.1080/15583058.2016.1207113

Jakiel, P., \& Fabianowski, D. (2015). FAHP model used for assessment of highway RC bridge structural and technological arrangements. Expert Systems with Applications, 42(8), 40544061. https://doi.org/10.1016/j.eswa.2014.12.039

Jato-Espino, D., Castillo-Lopez, E., Rodriguez-Hernandez, J., \& Canteras-Jordana, J. C. (2014). A review of application of multi-criteria decision making methods in construction. $\mathrm{Au}$ tomation in Construction, 45, 151-162.

https://doi.org/10.1016/j.autcon.2014.05.013

Jia, J., Ibrahim, M., Hadi, M., Orabi, W., \& Xiao, Y. (2018). Multi-criteria evaluation framework in selection of Accelerated Bridge Construction (ABC) method. Sustainability, 10(11), 4059. https://doi.org/10.3390/su10114059

Kaya, I., Çolak, M., \& Terzi, F. (2018). Use of MCDM techniques for energy policy and decision-making problems: a review. International Journal of Energy Research, 42(7), 2344-2372. https://doi.org/10.1002/er.4016

Keshavarz-Ghorabaee, M., Amiri, M., Zavadskas, E. K., Turskis, Z., \& Antucheviciene, J. (2018). Ranking of bridge design alternatives: A TOPSIS-FADR method. Baltic Journal of Road and Bridge Engineering, 13(3), 209-237.

https://doi.org/10.7250/bjrbe.2018-13.413

Kifokeris, D., Matos, J. A. C., Xenidis, Y., \& Bragança, L. (2018). Bridge quality appraisal methodology: Application in a reinforced concrete overpass roadway bridge. Journal of Infrastructure Systems, 24(4), 04018034.

https://doi.org/10.1061/(ASCE)IS.1943-555X.0000455

Kripka, M., Yepes, V., \& Milani, C. J. (2019). Selection of sustainable short-span bridge design in Brazil. Sustainability, 11(5), 1307. https://doi.org/10.3390/su11051307

Liu, L., Frangopol, D. M., Mondoro, A., \& Yang, D. Y. (2018). Sustainability-informed bridge ranking under scour based on transportation network performance and multiattribute utility. Journal of Bridge Engineering, 23(10), 04018082. https://doi.org/10.1061/(ASCE)BE.1943-5592.0001296

Malekly, H., Meysam-Mousavi, S., \& Hashemi, H. (2010). A fuzzy integrated methodology for evaluating conceptual bridge design. Expert Systems with Applications, 37(7), 49104920. https://doi.org/10.1016/j.eswa.2009.12.024
Mardani, A., Jusoh, A., Nor, K., Khalifa, Z., Zakwan, N., \& Valipour, A. (2015). Multiple criteria decision-making techniques and their applications - a review of the literature from 2000 to 2014. Economic Research-Ekonomska Istrazivanja, 28(1), 516-571. https://doi.org/10.1080/1331677X.2015.1075139

Mousavi, S. M., Gitinavard, H., \& Siadat, A. (2014). A new hesitant fuzzy analytical hierarchy process method for decisionmaking problems under uncertainty. In 2014 IEEE International Conference on Industrial Engineering and Engineering Management, Bandar Sunway, Malaysia.

https://doi.org/10.1109/IEEM.2014.7058713

Navarro, I. J., Yepes, V., \& Martí, A. (2018a). Life cycle cost assessment of preventive strategies applied to prestressed concrete bridges exposed to chlorides. Sustainability, 10(3), 845. https://doi.org/10.3390/su10030845

Navarro, I. J., Yepes, V., Martí, J. V., \& González-Vidosa, F. (2018b). Life cycle impact assessment of corrosion preventive designs applied to prestressed concrete bridge decks. Journal of Cleaner Production, 196, 698-713. https://doi.org/10.1016/j.jclepro.2018.06.110

Navarro, I. J., Yepes, V., Martí, J. V. (2018c). Social life cycle assessment of concrete bridge decks exposed to aggressive environments. Environmental Impact Assessment Review, 72, 50-63. https://doi.org/10.1016/j.eiar.2018.05.003

Navarro, I. J., Martí, J. V., Yepes, V., (2019a). Reliability-based maintenance optimization of corrosion preventive designs under a life cycle perspective. Environmental Impact Assessment Review, 74, 23-34. https://doi.org/10.1016/j.eiar.2018.10.001

Navarro, I. J., Yepes, V., \& Martí, J. V. (2019b). A review of multicriteria assessment techniques applied to sustainable infrastructure design. Advances in Civil Engineering, 2019, 6134803. https://doi.org/10.1155/2019/6134803

Navarro, I. J., Yepes, V., \& Martí, J. V. (2020). Sustainability assessment of concrete bridge deck designs in coastal environments using neutrosophic criteria weights. Structure and Infrastructure Engineering, 16(7), 949-967.

https://doi.org/10.1080/15732479.2019.1676791

Noryani, M., Sapuan, S. M., \& Matsura, M. T. (2018). Multi-criteria decision-making tools for material selection of natural fibre composites: A review. Journal of Mechanical Engineering and Sciences, 12(1), 3330-3353.

https://doi.org/10.15282/jmes.12.1.2018.5.0299

Ozcan-Deniz, G., \& Zhu, Y. (2015). A multi-objective decisionsupport model for selecting environmentally conscious highway construction methods. Journal of Civil Engineering and Management, 21(6), 733-747.

https://doi.org/10.3846/13923730.2014.893915

Pan, N. F. (2008). Fuzzy AHP approach for selecting the suitable bridge construction method. Automation in Construction, 17(8), 958-965. https://doi.org/10.1016/j.autcon.2008.03.005

Penadés-Plà, V., García-Segura, T., Martí, J. V., \& Yepes, V. (2016). A review of multi-criteria decision-making methods applied to the sustainable bridge design. Sustainability, 8(12), 1295. https://doi.org/10.3390/su8121295

Penadés-Plà, V., Martí, J. V., García-Segura, T., \& Yepes, V. (2017). Life-cycle assessment: A comparison between two optimal post-tensioned concrete box-girder road bridges. Sustainability, 9(10), 1864. https://doi.org/10.3390/su9101864

Penadés-Plà, V., García-Segura, T., \& Yepes, V. (2020a). Robust design optimization for low-cost concrete box-girder bridge. Mathematics, 8(3), 398. https://doi.org/10.3390/math8030398

Penadés-Plà, V., Martínez-Muñoz, D., García-Segura, T., Navarro, I. J., \& Yepes, V. (2020b). Environmental and social im- 
pact assessment of optimized post-tensioned concrete road bridges. Sustainability, 12(10), 4265.

https://doi.org/10.3390/su12104265

Peng, K. (2019). Risk evaluation for bridge engineering based on cloud-clustering group decision method. Journal of Performance of Constructed Facilities, 33(1), 04018105. https://doi.org/10.1061/(ASCE)CF.1943-5509.0001255

Pipinato, A., Rebelo, C., Pedrosa, B., \& Gervásio, H. (2020). Assessment procedure and rehabilitation criteria for riveted road bridges. Structural Engineering International, 30(1), 109-118. https://doi.org/10.1080/10168664.2019.1615855

Podvezko, V. (2011). The comparative analysis of MCDA methods SAW and COPRAS. Inzinerine Ekonomika - Engineering Economics, 22(2), 134-146.

https://doi.org/10.5755/j01.ee.22.2.310

Polat, G., Eray, E., \& Bingol, B. N. (2017). An integrated fuzzy mcgdm approach for supplier selection problem. Journal of Civil Engineering and Management, 23(7), 926-942. https://doi.org/10.3846/13923730.2017.1343201

Radwan, N., Senousy, M., \& Riad, A. (2016). Neutrosophic AHP multi-criteria decision making method applied on the selection of learning management system. International Journal of Advancements in Computing Technology, 8(5), 95-105.

Rashidi, M., Ghodrat, M., Samali, B., Kendall, B., \& Zhang, C. (2017). Remedial modelling of steel bridges through application of analytical hierarchy process (AHP). Applied Sciences, 7(2), 168. https://doi.org/10.3390/app7020168

Rempling, R., Mathern, A., Tarazona-Ramos, D., \& Luis-Fernández, S. (2019). Automatic structural design by a set-based parametric design method. Automation in Construction, 108, 102936. https://doi.org/10.1016/j.autcon.2019.102936

Sabatino, S., Frangopol, D. M. \& Dong, Y. (2015). Sustainabilityinformed maintenance optimization of highway bridges considering multi-attribute utility and risk attitude. Engineering Structures, 102, 310-321.

https://doi.org/10.1016/j.engstruct.2015.07.030

Sabatino, S., Frangopol, D. M. \& Dong, Y. (2016). Life cycle utility-informed maintenance planning based on lifetime functions: optimum balancing of cost, failure consequences and performance benefit. Structure and Infrastructure Engineering, 12(7), 830-847.

https://doi.org/10.1080/15732479.2015.1064968

Salas, J., \& Yepes, V. (2020). Enhancing sustainability and resilience through multi-level infrastructure planning. Environmental Research and Public Health, 17(3), 962. https://doi.org/10.3390/ijerph17030962

Salem, O., Salman, B., \& Ghorai, S. (2018). Accelerating construction of roadway bridges using alternative techniques and procurement methods. Transport, 33(2), 567-579. https://doi.org/10.3846/16484142.2017.1300942

Sánchez-Garrido, A. J., \& Yepes, V. (2020). Multi-criteria assessment of alternative sustainable structures for a self-promoted, single-family home. Journal of Cleaner Production, 258, 120556. https://doi.org/10.1016/j.jclepro.2020.120556

Sasmal, S., \& Ramanjaneyulu, K. (2008). Condition evaluation of existing reinforced concrete bridges using fuzzy based analytic hierarchy approach. Expert Systems with Applications, 35(3), 1430-1443. https://doi.org/10.1016/j.eswa.2007.08.017

Schmidt, J.-S., \& Osebold, R. (2017). Environmental management systems as a driver for sustainability: state of implementation, benefits and barriers in German construction companies. Journal of Civil Engineering and Management, 23(1), 150-162. https://doi.org/10.3846/13923730.2014.946441

Senapati, T., \& Yager, R. R. (2019). Some new operations over fermatean fuzzy numbers and application of fermatean fuzzy
WPM in multiple criteria decision making. Informatica, 30(2), 391-412. https://doi.org/10.15388/Informatica.2019.211

Sierra, L. A., Pellicer, E., \& Yepes, V. (2017). Method for estimating the social sustainability of infrastructure projects. Environmental Impact Assessment Review, 65, 41-53.

https://doi.org/10.1016/j.eiar.2017.02.004

Shen, F., Xu, J., \& Xu, Z. (2016). An outranking sorting method for multi-criteria group decision making using intuitionistic fuzzy sets. Information Sciences, 334-335, 338-353.

https://doi.org/10.1016/j.ins.2015.12.003

Sobanjo, J. O., Stukhart, G., \& James, R. W. (1994). Evaluation of projects for rehabilitation of highway bridges. Journal of Structural Engineering, 120(1), 81-99. https://doi.org/10.1061/(ASCE)0733-9445(1994)120:1(81)

Tan, J. S., Elbaz, K., Wang, Z. F., Shen, J. S., \& Chen, J. (2020). Lessons learnt from bridge collapse: A view of sustainable management. Sustainability, 12(3), 1205.

https://doi.org/10.3390/su12031205

Torres-Machi, C., Pellicer, E., Yepes, V., \& Chamorro, A. (2017). Towards a sustainable optimization of pavement maintenance programs under budgetary restrictions. Journal of Cleaner Production, 148, 90-102.

https://doi.org/10.1016/j.jclepro.2017.01.100

Ugwu, O. O., Kumaraswamy, M. M., Wong, A., \& Ng, S. T. (2006). Sustainability appraisal in infrastructure projects (SUSAIP): Part 2: A case study in bridge design. Automation in Construction, 15(2), 229-238.

https://doi.org/10.1016/j.autcon.2005.05.005

UNEP/SETAC. (2009). Guidelines for social life cycle assessment of products. United Nations Environment Program. In Paris SETAC Life Cycle Initiative United Nations Environment Programme.

Wang, W. (2017). On fuzzy TOPSIS method based on alpha level sets. Journal of Intelligent and Fuzzy Systems, 33(6), 4067-4076. https://doi.org/10.3233/JIFS-17983

Wang, Y. M., \& Elhag, T. M. S. (2006). Fuzzy TOPSIS method based on alpha level sets with an application to bridge risk assessment. Expert Systems with Applications, 31(2), 309-319. https://doi.org/10.1016/j.eswa.2005.09.040

Wang, Y. M., \& Elhag, T. M. S. (2007). A fuzzy group decision making approach for bridge risk assessment. Computers and Industrial Engineering, 53(1), 137-148. https://doi.org/10.1016/j.cie.2007.04.009

Wang, Y. M., Liu, J., \& Elhag, T. M. S. (2008). An integrated AHP-DEA methodology for bridge risk assessment. Computers and Industrial Engineering, 54(3), 513-525. https://doi.org/10.1016/j.cie.2007.09.002

Wang, J. C., \& Chen, T. Y. (2015). Likelihood-based assignment methods for multiple criteria decision analysis based on interval-valued intuitionistic fuzzy sets. Fuzzy Optimization and Decision Making, 14(4), 425-457. https://doi.org/10.1007/s10700-015-9208-6

Wang, H. L., Qin, S. F., Zhang, Z., \& Huang, C. L. (2010). Fuzzy optimum model of semi-structural decision for bridge lectotype. In 7th International Conference on Fuzzy Systems and Knowledge Discovery, Yantai, China. https://doi.org/10.1109/FSKD.2010.5569102

Wang, Z., Jin, W. L., Wu, K., \& Frangopol, D. M. (2018). Social dimensions in sustainability evaluation of deteriorating reinforced concrete bridges. In 6th International Conference on Durability of Concrete Structures.

World Commission on Environment and Development. (1987). Our common future. 
Yadollahi, M., Ansari, R., Abd-Majid, M. Z., \& Yih, C. H. (2015). A multi-criteria analysis for bridge sustainability assessment: a case study of Penang Second Bridge, Malaysia. Structure and Infrastructure Engineering, 11(5), 638-654. https://doi.org/10.1080/15732479.2014.893002

Yehia, S., Abudayyeh, O., Fazal, I., \& Randolph, D. (2008). A decision support system for concrete bridge deck maintenance. Advances in Engineering Software, 39(3), 202-210. https://doi.org/10.1016/j.advengsoft.2007.02.002

Yepes, V., García-Segura, T., \& Moreno-Jiménez, J. M. (2015). A cognitive approach for the multi-objective optimization of RC structural problems. Archives of Civil and Mechanical Engineering, 15(4), 1024-1036. https://doi.org/10.1016/j.acme.2015.05.001

Zastrow, P., Molina-Moreno, F., García-Segura, T., Martí, J.V., \& Yepes, V. (2017). Life cycle assessment of cost-optimized buttress earth-retaining walls: a parametric study. Journal of Cleaner Production, 140, 1037-1048.

https://doi.org/10.1016/j.jclepro.2016.10.085

Zavadskas, E. K., Govindan, K., Antucheviciene, J., \& Turskis, Z. (2016a). Hybrid multiple criteria decision-making methods: a review of applications for sustainability issues. Economic Research-Ekonomska Istraživanja, 29(1), 857-887. https://doi.org/10.1080/1331677X.2016.1237302

Zavadskas, E. K., Antucheviciene, J., Turskis, Z., \& Adeli, H. (2016b). Hybrid multiple-criteria decision-making methods: A review of applications in engineering. Scientia Iranica A, 23(1), 1-20.

Zavadskas, E. K., Antucheviciene, J, \& Kaplinski, O. (2016c). Multi-criteria decision making in civil engineering: Part I - a state-of-the-art survey. Engineering Structures and Technologies, 7(3), 103-113. https://doi.org/10.3846/2029882X.2015.1143204

Zavadskas, E. K., Antucheviciene, J., \& Kaplinski, O. (2016d). Multi-criteria decision making in civil engineering. Part II applications. Engineering Structures and Technologies, 7(4), 151-167. https://doi.org/10.3846/2029882X.2016.1139664

Zavadskas, E. K., Antucheviciene, J., Vilutiene, T., \& Adeli, H. (2018). Sustainable decision-making in civil engineering, construction and building technology. Sustainability, 10(1), 14. https://doi.org/10.3390/su10010014

Zhang, Y. R., Wu, W. J., \& Wang, Y. F. (2016). Bridge life cycle assessment with data uncertainty. The International Journal of Life Cycle Assessment, 21, 569-576.

https://doi.org/10.1007/s11367-016-1035-7 